\title{
Segregation ratio in cranio-cerebello-cardiac syndrome
}

\author{
Harm-Jan Stellingwerff ${ }^{1}$, Johanna M van Hagen $^{1}$ and Leo P ten Kate*,1 \\ ${ }^{1}$ Department of Clinical Genetics and Human Genetics, VU University Medical Center, Amsterdam, The Netherlands
}

According to several authors cranio-cerebello-cardiac (3C) syndrome is an autosomal recessive disorder. This opinion was based on pedigree inspection without formal segregation analysis. Recently, the assumption of autosomal recessive inheritance was challenged by the observation of overlapping features with $6 p$ deletions. We therefore performed segregation analysis by means of methods described by Li and Mantel, Davie and Lange on 27 pedigrees selected from literature. The results of all three methods are consistent with autosomal recessive inheritance but their broad confidence intervals leave room for other explanations as well. Reporting of $3 C$ cases without evaluation of $6 p$ copy number should be discouraged from now on.

European Journal of Human Genetics (2006) 14, 1054-1057. doi:10.1038/sj.ejhg.5201660; published online 31 May 2006

Keywords: cranio-cerebello-cardiac syndrome; 3C syndrome; Ritscher-Schinzel syndrome; segregation analysis

\section{Introduction}

The cranio-cerebello-cardiac (3C) syndrome or RitscherSchinzel syndrome was first described by D Ritscher and A Schinzel from Switzerland in $1987^{1}$ in two sisters with craniofacial, cerebellar and cardiac abnormalities. In 2001 Leonardi et $a l^{2}$ reported four new cases and reviewed previously published cases. $^{3-15}$ According to Leonardi et $a l^{2}$ the following criteria define the syndrome:

1. congenital heart malformation(s) other than patent ductus arteriosus alone

2. Dandy-Walker malformation, cerebellar vermis hypoplasia, or enlarged cisterna magna

3. cleft palate, ocular coloboma, or four of the following: prominent occiput, prominent forehead, hypertelorism, micrognathia, downslanting palpebral fissures, and depressed nasal bridge.

*Correspondence: Professor LP ten Kate, Department of Clinical Genetics and Human Genetics, VU University Medical Center, PO Box 7057, 1007 MB Amsterdam, The Netherlands.

Tel: + 3120 4440786; Fax: + 3120 4444181; E-mail: Ip.tenkate@vumc.nl Received 4 April 2005; revised 13 February 2006; accepted 19 April 2006; published online 31 May 2006
It is generally assumed that 3C syndrome is an autosomal recessive disorder. This assumption is based on pedigree inspection and the existence of parental consanguinity in two families. The responsible gene has not been identified so far. Recently, DeScipio et $a l^{16}$ called attention to the phenotypic overlap with 6 p25 deletions, but could not find such deletions nor mutations in three forkhead genes in or near this region in seven unrelated $3 \mathrm{C}$ syndrome patients. In their discussion they question autosomal recessive inheritance of the syndrome. Innes ${ }^{17}$ stressed the importance of ruling out a terminal $6 p$ deletion in suspected cases of $3 \mathrm{C}$ syndrome.

In this article, the hypothesis of recessive inheritance will be tested by means of formal segregation analysis in families published in the medical literature. Three estimation methods will be used. These are, in order of publication: the method according to $\mathrm{Li}$ and Mantel, ${ }^{18}$ the method according to Davie ${ }^{19}$ and the method according to Lange. ${ }^{20}$ The method of $\mathrm{Li}$ and Mantel assumes complete ascertainment; the method according to Davie assumes single selection and the method according to Lange uses neither assumption, but estimates the segregation fraction through subsequent steps of Expectation and Maximisation (EM algorithm). 


\section{Pedigrees and methods}

The pedigrees

We selected all families reported and reviewed by Leonardi et $a l^{2}$ and added four more families fulfilling the criteria set forth by them. We accepted the patient described by Wheeler et $a l^{21}$ in 1999 as a case of 3C syndrome, as did Zankl et al. ${ }^{22}$ We also included three more recently described families. One by Hordijk et al, ${ }^{23}$ one by Garavelli et $a l,{ }^{24}$ and one by Papadopoulou et al. ${ }^{26}$ In their presentation Hordijk et $a l^{23}$ mentioned that the mother was pregnant of a third child. Later inquiry showed this child to be a girl with the 3C syndrome (R Hordijk, personal communication). In total, we included in our analysis 27 families with 34 patients. The pedigrees are shown in Supplementary Figure 1, ordered by publication date. Consanguinity of the parents was reported in two families, ${ }^{9,15}$ one Aboriginal Canadian and one Pakistani. Table 1 summarises the data by family size and number of affected sibs.

\section{Statistical analysis}

As in an autosomal recessive disorder in general both sexes have an equal probability of being affected, we checked first the distribution of sexes by $\chi^{2}$ analysis with Yates correction and one degree of freedom. We then moved on to segregation analysis by means of the three methods mentioned before:

The method of Li-Mantel is based on the assumption of complete ascertainment. This means that all affected children are ascertained independently from their affected siblings. This assumption leads to the following estimation formula:

$$
p_{\mathrm{LM}}=\frac{\left(R-J_{1}\right)}{\left(T-J_{1}\right)}
$$

Here, $p_{\mathrm{LM}}$ stands for the segregation ratio, $R$ stands for the total number of affected children, $J_{1}$ stands for the total number of families with only one affected child and $T$ stands for the total number of affected and unaffected offspring. Variance for this estimation is calculated using weighting tables created by $\mathrm{Li}$ and Mantel. The tables contain weighted terms representing families of different

Table 1 Distribution of families by size and number of affected children

\begin{tabular}{lcccccc}
\hline & & \multicolumn{5}{c}{$\begin{array}{c}\text { Number of families } \\
\text { by number of sibs }\end{array}$} \\
$\begin{array}{l}\text { Affected sibs } \\
\text { per family }(n)\end{array}$ & Families $(n)$ & 1 & 2 & 3 & 4 & 5 \\
\hline 1 & 22 & 8 & 9 & 1 & 2 & 2 \\
2 & 3 & 0 & 0 & 1 & 2 & 0 \\
3 & 2 & 0 & 0 & 1 & 0 & 1 \\
Total & 27 & 8 & 9 & 3 & 4 & 3 \\
\hline
\end{tabular}

sizes. The variance is the reciprocal of the sum of these terms. Standard error was then calculated by taking the square root of the variance.

The method of Davie is based on the assumption of single selection. This means that there is a low probability of ascertainment of affected children so that affected families are ascertained once at most. This leads to this formula:

$$
p_{\mathrm{D}}=\frac{(R-J)}{(T-J)}
$$

Here, $p_{\mathrm{D}}$ stands for the segregation ratio, $R$ again stands for the total number of affected children, $J$ stands for the total number of families and $T$ again stands for the total number of offspring. The variance is calculated using the following formula:

$$
\operatorname{var} p_{\mathrm{D}}=\frac{(R-J)(T-R))}{(T-J)^{3}}
$$

Standard error is calculated by taking the square root of this variance.

The method of Lange uses an EM algorithm to estimate the segregation proportion. EM algorithms use the observed data to estimate the missing data. In the case of segregation analysis the observed data consists of the families found in the publications and the missing data being both the segregation ratio $\left(p_{\mathrm{EM}}\right)$ and the ascertainment probability $\left(\pi_{\mathrm{EM}}\right)$. Lange adjusted the EM algorithm to the use for segregation analysis. Yielding the following formulae:

$$
\begin{aligned}
p_{m+1} & =\frac{\sum\left[r_{k}+\frac{s_{k} p_{m}\left(1-\pi_{m}\right)\left(1-p_{m} \pi_{m}\right)^{s_{k}-1}}{1-\left(1-p_{m} \pi_{m}\right)^{s_{k}}}\right]}{\sum s_{k}\left[1+\frac{\left(1-p_{m} \pi_{m}\right)^{s_{k}}}{1-\left(1-p_{m} \pi_{m}\right)^{s_{k}}}\right]} \\
\pi_{m+1} & =\frac{\sum a_{k}}{\sum\left[r_{k}+\frac{s_{k} p_{m}\left(1-\pi_{m}\right)\left(1-p_{m} \pi_{m}\right)^{s_{k}-1}}{1-\left(1-p_{m} \pi_{m}\right)^{s_{k}}}\right]}
\end{aligned}
$$

In these formulae:

- $a_{k}$ stands for the number of ascertained children in family $k$,

- $\mathrm{p}_{m}$ stands for the estimated segregation ratio after going through the algorithm $m$ times,

- $\pi_{m}$ stands for the estimated ascertainment probability after going through the algorithm $m$ times,

- $r_{k}$ stands for the number of affected children in family $k$,

- $s_{k}$ stands for the number of children in children in family $k$.

The starting values for $p$ and $\pi$ can be any number between one and zero. After a number of steps $p$ no longer changes significantly. After an infinite steps $\pi$ will become 0 since the algorithm continually increases the test population and therefore the number of affected children. 
With only a limited number of children found and infinite number of children affected the chance of finding an affected child goes to zero.

Bootstrapping was used to obtain the 95\% probability interval for the Davie estimate. This method of getting a probability interval was described by Efron and Tibshirani. $^{25}$

Bootstrapping implies that from the original test group new test groups (typically 1000) are created, all of which have the same number of families as the original group but the families are taken randomly from the original test group. For each new group the segregation ratio is calculated. From these results the $95 \%$ probability interval is calculated.

\section{Results}

The male to female ratio of the affected patients in the pedigrees was $11: 23$. This is not significantly different from a $1: 1$ ratio $\left(\chi^{2}=3.56 ; P>0.05\right)$.

The results of the segregation analysis were as follows:

The estimated segregation proportion with (between brackets) the lower and upper boundaries of the estimates were: for the method of Li and Mantel: 0.27 (0.11-0.44); for the method of Davie $0.18(0.06-0.30)$ and for the method of Lange $0.18(0.05-0.32)$.

\section{Discussion}

The three methods of segregation analysis are unanimous in the inclusion of $25 \%$, meaning that the data are compatible with the hypothesis of autosomal recessive inheritance. The three methods also agree on rather broad confidence intervals. No doubt this is a reflection of the limited number of families that could be studied. It means, however, that the argument in favour of autosomal recessive inheritance, based on our segregation analysis, should not be overemphasised, as long as other mechanisms such as a $6 \mathrm{p}$ deletion have not been excluded. This was, of course, not possible as our study was restricted to published families. In the future reporting of 3C syndrome cases without assessment of $6 p$ copy number should be discouraged. Repetition of segregation analysis when more families are reported in which $6 \mathrm{p}$ deletions are excluded, is indicated, until molecular proof of its aetiology for all cases of $3 \mathrm{C}$ syndrome can be found.

A third agreement of all three methods should be mentioned for the sake of completeness. All exclude a segregation ratio of $50 \%$, meaning that the data are not compatible with autosomal dominant inheritance with high penetrance. This is not surprising since only affected siblings, and no other affected family members have been reported. The presence of consanguinity in two families also supports the assumption of recessive inheritance. Consanguinity, however, is no exception in the commu- nities to which these families belonged, ${ }^{27,28}$ decreasing the strength of this argument.

In comparing the estimates and confidence intervals of the different methods it seems that the results of applying the method of Davie and the method of Lange agree very well, and that the result of applying the method of Li and Mantel is different. This is not unexpected since the method of Li and Mantel assumes complete ascertainment, which is a very unlikely assumption in a study based on families reported in literature.

Our data do not point to substantial genetic heterogeneity so far, but cannot exclude this either. We also cannot be sure that the families reported in the literature are representative for all other families with the $3 \mathrm{C}$ syndrome. It is even not unlikely that there is a reporting bias towards familial cases. On the other hand, many of the reported families have only one child and it is not known whether the parents had more children after publication of the family data.

In conclusion, the hypothesis of autosomal recessive inheritance of 3C syndrome cannot be rejected on the basis of segregation analysis at this moment. In the future reporting of $3 \mathrm{C}$ cases without assessment of $6 \mathrm{p}$ copy number should be discouraged.

\section{References}

1 Ritscher D, Schinzel A, Boltshauser E, Briner J, Arbenz U, Sigg P: Dandy-Walker(like) malformation, atrio-ventricular septal defect and a similar pattern of minor anomalies in 2 sisters: a new syndrome? Am J Med Genet 1987; 26: 481-491.

2 Leonardi ML, Shashidbar Pai G, Wilkes B, Lebel RR: RitcherSchinzel cranio-cerebello-cardiac(3C) syndrome: report of four new cases and review. Am J Med Genet 2001; 102: 237-242.

3 Verloes A, Dresse MF, Jovanovic M, Dodinval P, Geubelle F: 3C syndrome: third occurrence of cranio-cerebello-cardiacdysplasia (Ritcher-Schinzel syndrome). Clin Genet 1989; 35: 205-208.

4 Mims LRC, Say B: 3C syndrome: another case. Clin Genet 1989; 36: 465.

5 Gurrieri F, Neri G: An additional patient with the 3C syndrome. Clin Genet 1992; 41: 263-265.

6 Wörle H, Lewin MAG, Holder M, Bastanier CK, Köhler B: Another case of Ritcher-Schinzel-syndrome: cranio-cerebello-cardiacdysplasia (3C-syndrome) with associated bilateral colobomata. Eur J Pediatr 1994; 153: 140-142.

7 Hoo JJ, Kreiter M, Halverson N, Perszyk A: 3C (cranio-cerebellocardiac) syndrome: a recently delineated and easily recognizable congenital malformation syndrome. Am J Med Genet 1994; 52: 66-69.

8 Quintana A, Alonso A, Lorenzo O, Belanger A: Dandy-Walker malformation, cardiac defect and deafness: a variation of the cranio-cerebello-cardiac dysplasia (Ritcher-Schinzel syndrome). Genet Couns 1994; 5: 144A.

9 Marles SL, Chodirker BN, Greenberg CR, Chudley AE: Evidence for Ritscher-Schinzel syndrome in Canadian native Indians. Am J Med Genet 1995; 56: 343-350.

10 Saraiva JM, Gama E, Moreira Pires M, Sequiera JF: First report of glaucoma as a feature of the 3C syndrome. Clin Dysmorphol 1995; 4: $156-160$.

11 Digilio MC, Marino B, Giannotti A, Mingarelli R, Dallapiccola B: Atrioventricular canal and 3C (cranio-cerebello-cardiac) syndrome. Am J Med Genet 1995; 58: 97-98. 
12 Marazzo DP, Mulvihill JJ: Unusual features in a neonate with 3C (cranio-cerebello-cardiac) syndrome. Am J Hum Genet (suppl) 1995; 57: 96.

13 Lurie I, Ferencz C: 'Shifted' threshold may explain diversity of cardiovascular malformations in multiple congenital abnormalities syndromes. 3C (Ritscher-Schinzel) syndrome as an example. Am J Med Genet 1996; 66: 72-74.

14 Kosaki K, Curry CJ, Roeder E, Jones KL: Ritscher-Schinzel (3C) syndrome: documentation of the phenotype. Am J Med Genet 1997; 68: $421-427$.

15 Ørstavik K, Bechensteen A, Fugelseth D, Orderud W: Sibs with Ritscher-Schinzel (3C) syndrome and anal malformations. Am J Med Genet 1998; 75: 300-303.

16 DeScipio C, Schneider L, Young TL et al: Subtelomeric deletions of chromosome $6 \mathrm{p}$ : molecular and cytogenetic characterization of three new cases with phenotypic overlap with Ritscher-Schinzel (3C) syndrome. Am J Med Genet 2005; 134A: 3-11.

17 Innes AM: Re: 3C (Ritscher-Schinzel) syndrome: the importance of ruling out a terminal 6p deletion. Clin Dysmorphol 2005; 14: 209-210.

18 Li CC, Mantel N: A simple method of estimating the segregation ratio under complete ascertainment. Am Hum Genet 1968; 20: $61-81$.

19 Davie AM: The 'singles' method for segregation analysis under incomplete ascertainment. Ann Hum Genet 1979; 42: 507-512.
20 Lange K: Mathematical and Statistical Methods for Genetic Analysis. New York: Springer, 1997.

21 Wheeler PG, Sadeghi-Nejad A, Elias ER: The 3C syndrome: evolution of the phenotype and growth hormone deficiency. Am I Med Genet 1999; 87: 61-64.

22 Zankl A, Gungor T, Schinzel A: (3C) syndrome: follow-up study of the original patient. Am J Med Genet. 2003; 118A: 55-59.

23 Hordijk R, Fock A, Visser G, Niezen K, Van Essen T: A twin with 3C syndrome. Genet Couns 2001; 12: 184.

24 Garavelli L, Donadio A, Muzzini S et al: 3C (cranio-cerebellocardiac) syndrome (Ritscher-Schinzel syndrome): a new case? Genet Couns 2001; 12: 185.

25 Efron B, Tibshirani RJ: An Introduction to the Bootstrap. New York: Chapman \& Hall, 1993.

26 Papadopoulou E, Sifakis S, Rogalidou M, Makrigiannakis A, Giannakopoulou C, Petersen MB: 3C syndrome with cryptorchidism and posterior embryotoxon. Clin Dysmorphol 2005; 14: 97-100.

27 Evans JA, Hunter AG, Thompson DR, Ramsay S: A study of institutionalized mentally retarded patients in Manitoba: overrepresentation by Canadian Indian children. J Ment Defic Res 1985; 29: $153-164$.

28 Houssain R, Bittles AH: The prevalence and demographic characteristics of consanguineous marriages in Pakistan. J Biosoc Sci 1998; 30: 261-275.

Supplementary Information accompanies the paper on European Journal of Human Genetics website (http://www.nature.com/ejhg) 